\title{
Resiliência pedagógica: escolas ribeirinhas frente às variações de seca e cheia do Rio Amazonas
}

\author{
Danielle Golvim da Silva Alencar ${ }^{1}$ \\ ORCID: 0000-0002-9447-8069 \\ Francimara Souza da Costa ${ }^{1}$ \\ ORCID: 0000-0003-4352-0826
}

\section{Resumo}

Resiliência pedagógica pode ser compreendida como uma estratégia que viabiliza de maneira prática e qualitativa a adaptação do professor às situações adversas que surgem em seu ambiente de ensino, principalmente em realidades educacionais não convencionais, como aquelas vivenciadas por escolas localizadas nas margens dos rios da Amazônia. Este estudo objetivou analisar o processo de resiliência pedagógica de professores de uma escola ribeirinha localizada no município de Careiro da Várzea, Estado do Amazonas, considerando três fatores básicos: a formação do professor, o currículo escolar e as práticas educacionais realizadas. Para a realização da pesquisa foi utilizada a abordagem qualitativa e os dados foram coletados por meio de análise documental, pesquisa bibliográfica e entrevistas com professores e gestora da escola. Os resultados demonstram que o currículo escolar possui estrutura semelhante ao currículo de escolas urbanas, mas os professores tentam adaptá-lo à sua realidade, ainda que de forma parcial. Foi observada a ausência de uma formação específica para atuação dos professores na educação ribeirinha e a necessidade de um processo de adaptação constante das práticas educativas, de acordo com a sazonalidade de seca e cheia do Rio Amazonas. Tais necessidades resultam em reelaborações curriculares e de planejamentos, mudanças sazonais de estratégias de aulas e criação de práticas, além da necessidade de adaptação do ambiente escolar à falta de material e de infraestrutura adequada.

\section{Palavras chaves}

Resiliência - Amazônia - Escolas ribeirinhas.

1 - Universidade Federal do Amazonas, Manaus, Amazonas, Brasil. Contatos: daniellegolvim@outlook.com; francimaracosta@yahoo.com.br 


\section{Pedagogical resilience: riverside schools in the face of drought and floods in the Amazon River}

\section{Abstract}

Pedagogical resilience can be understood as a strategy that enables, in a practical and qualitative way, the adaptation of the teacher to the adverse situations that arise in his or her teaching environment, mainly in unconventional educational realities, such as those experienced by schools located on the banks of the rivers of the Amazonia. This study aimed to analyze the process of pedagogical resilience of teachers from a riverside school located in the municipality of Careiro da Várzea, State of Amazonas, considering three basic factors: teacher training, school curriculum and educational practices carried out. To conduct the research, the qualitative approach was used and data were collected through document analysis, bibliographic review and interviews with teachers and the school manager. The results show that the school curriculum has a similar structure to the curriculum of urban schools, but teachers try to adapt it to their reality, even if in a partial way. The absence of specific training was observed for the performance of teachers in riverside education and the need for a process of constant adaptation of educational practices, according to the drought and flood seasons of the Amazon River. Such needs result in curricular and planning re-elaborations, seasonal changes in class strategies and the creation of practices, in addition to the need to adapt the school environment to the lack of materials and adequate infrastructure.

\section{Keywords}

Resilience - Amazon - Riverside schools.

\section{Introdução}

0 processo de resiliência no ser humano pode ser compreendido como a aquisição da capacidade de uma pessoa, grupo ou comunidade de prevenir, minimizar ou dominar os efeitos negativos dos momentos de dificuldade (GROTBERG, 2005). Em termos gerais, a resiliência representa o retorno ao estado normal após uma adversidade ou perturbação, porém, seu significado depende de suas bases teóricas, sendo empregado também nas áreas de psicologia, administração, ecologia e física (CASTRO, 2001).

No campo da pedagogia, a resiliência é vista como uma estratégia que viabiliza de maneira prática e qualitativa a adaptação do professor às situações adversas que surgem em seu ambiente de ensino (TAVARES, 2014), principalmente quando a realidade educacional está fora dos quesitos convencionais, como as escolas do campo por exemplo, que possuem um meio social diferenciado.

Nas áreas rurais, o processo educacional abrange espaços da floresta, rios, campos, pequenas agroindústrias, áreas de convivência coletiva, roçados, dentre outros. Constitui- 
se em um processo diferenciado daquele que ocorre nas escolas urbanas, pois destina-se a populações que possuem uma relação direta com o ambiente em que vivem, em meio a atividades relacionadas à produção agrícola, pesca, criação animal e extrativismo.

A Lei de Diretrizes e Bases da Educação Nacional (LDB) diz, no artigo 28ª que na oferta da Educação Básica para a população rural, os sistemas de ensino deverão promover adaptações para a sua adequação às peculiaridades de cada região, ou seja, devem ser autônomas quanto a sua organização escolar, metodologias e calendário, adequando a estrutura escolar às suas necessidades e realidade (BRASIL, 1996). Todavia, as escolas do campo reproduzem o modelo educacional das escolas urbanas, limitando o desenvolvimento do pensamento crítico e acesso à cidadania, implementando nas áreas rurais a educação elitista e instrumental voltada apenas para o mercado de trabalho (BRITO, 2015).

Além do uso de metodologias de ensino inadequadas, as escolas rurais do Estado do Amazonas enfrentam diversos problemas que limitam o acesso ao ensino de qualidade. Possuem infraestrutura precária, com espaços constituídos de uma sala para um elevado número de alunos, sofrem com ausência de laboratórios, bibliotecas e recursos eletrônicos, dificuldades de acesso à energia elétrica, além da precariedade do abastecimento de água e das condições sanitárias. Estes fatores resultam em altas taxas de analfabetismo, distorção idade-série e baixa qualificação dos estudantes.

Nas escolas ribeirinhas, a comunidade escolar enfrenta, ainda, anualmente, as alterações naturais dos rios, havendo necessidades específicas que precisam ser consideradas nas estratégias de planejamento e gestão educacional. 0 Estado do Amazonas conta com períodos de enchente, cheia, vazante e seca, que configuram todo o modo de vida das populações ribeirinhas, modificando as formas de transporte, atividades econômicas e organização social.

Diante dessa realidade, os educadores necessitam de preparo material e emocional para enfretamento das dificuldades e construção de mecanismos de resiliência. Porém, nas áreas rurais, principalmente em áreas ribeirinhas onde a dificuldade de acesso é maior devido às grandes distâncias das cidades, a maioria dos professores não possui formação adequada para atuar nesse sistema educacional, o que resulta em alta rotatividade e baixo rendimento escolar (RODRIGUES, 2009).

Poucos estudos científicos têm se voltado para compreensão da construção do processo de resiliência por educadores que enfrentam dificuldades adversas no ambiente escolar. Essa pesquisa buscou analisar essa realidade em uma escola ribeirinha do município de Careiro da várzea, no Estado do Amazonas, apontando as adaptações ocorridas na escola e os mecanismos de resiliência pedagógica dos professores diante das alterações de seca e cheia do Rio Amazonas. Para essa compreensão, foram analisados três fatores: a avaliação do currículo, a formação dos professores e as práticas pedagógicas relacionadas ao processo de resiliência.

0 estudo contribui para a expansão do conhecimento acerca da realidade da educação do/no campo na Amazônia, notadamente das escolas localizadas em ambientes ribeirinhos, considerando suas peculiaridades e dificuldades. A compreensão do processo de resiliência pedagógica nessas áreas é necessária para a elaboração de políticas públicas 
e programas educacionais mais adequados, capazes de contribuir para minimização dos problemas e melhorias dos processos educacionais nesses ambientes.

\section{Percurso metodológico}

\section{Área de estudo}

A pesquisa foi realizada em uma Escola Municipal ribeirinha localizada à margem direita do Rio Amazonas, no município de Careiro da Várzea/AM (figura 01). A escola oferece Educação Infantil e Ensino Fundamental I (Séries Iniciais) durante o turno matutino e Ensino Fundamental II (Séries Finais) no turno vespertino. Tem capacidade para 400 alunos, mas conta com 114 alunos matriculados.

Figura 01- Localização da área de pesquisa

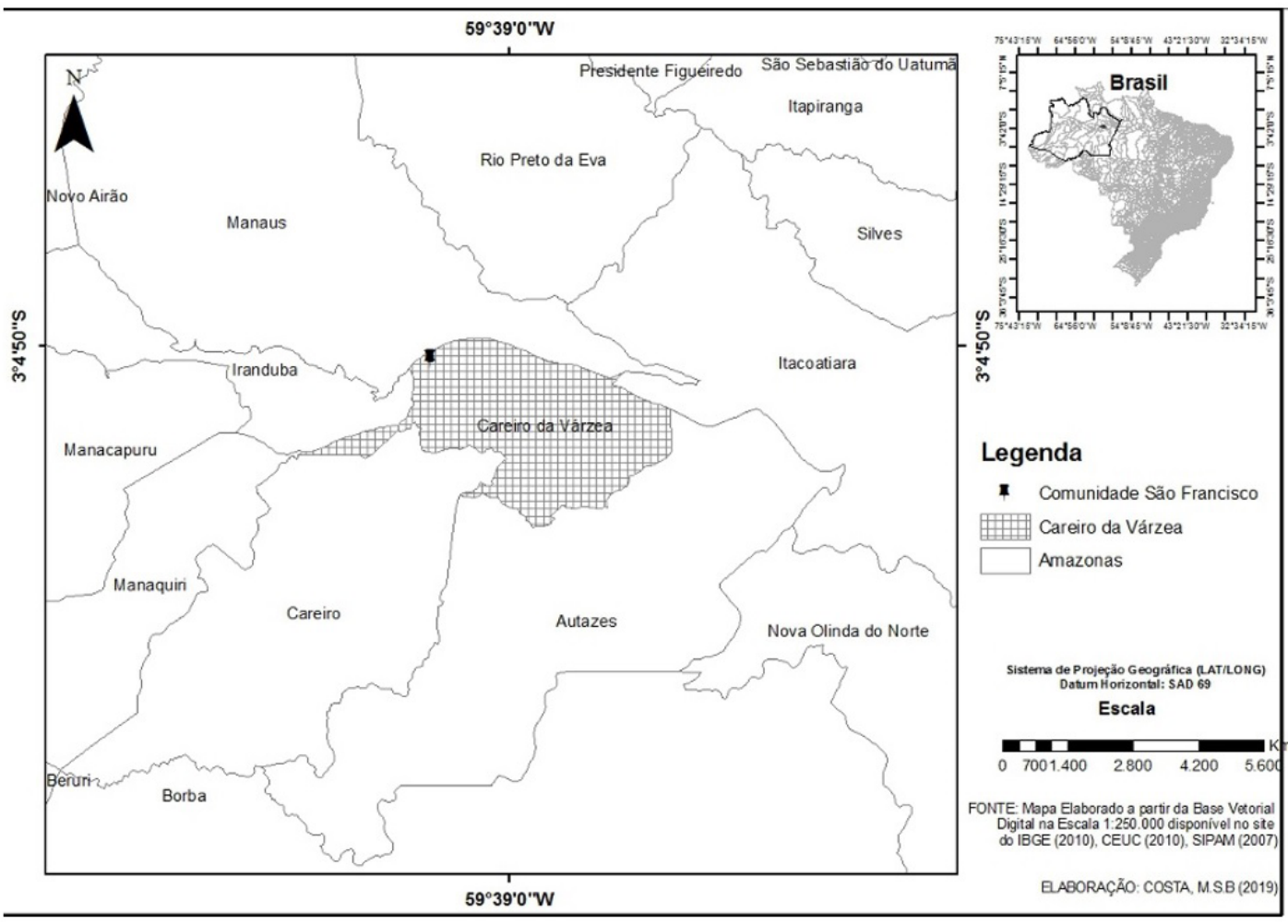

Fonte: Mapa elaborado a partir da base vetorial digital disponível no site do IBGE (2010), CEUC (2010) e SIPAM (2007).

0 público atendido pela escola é oriundo de três comunidades locais, que estão assentadas em uma área de várzea praticante da agricultura familiar, centrada em sistemas agroflorestais de uso e manejo tradicionais. As atividades de trabalho realizadas pela maioria das famílias para obtenção de renda são a agricultura, pecuária, pesca, extrativismo, comércio e serviços públicos municipais e estaduais. A prática do cultivo 
tem como base a mão-de-obra familiar e os principais produtos comercializados são hortaliças, plantas medicinais e ornamentais (NASCIMENTO, 2017).

As comunidades dessa localidade estão sujeitas às variações de cheia e seca do Rio Amazonas, que tem grande influência na organização social e econômica dos moradores. $\mathrm{Na}$ cheia, a pesca torna-se uma das principais atividades e no tempo de seca é a vez da agricultura, com uma importante safra de hortaliças, proporcionando, assim, uma economia temporária de acordo com as condições do ambiente natural. Como complemento de renda, as famílias que recebem menos de um salário mínimo são beneficiadas com o programa bolsa família e o seguro defeso do Governo Federal.

\section{Coleta e análise de dados}

A pesquisa foi orientada por uma abordagem qualitativa, baseada na obtenção de informações junto aos participantes ativos da realidade educacional estudada. Segundo Gerhardt e Silveira (2009), a pesquisa qualitativa refere-se não à preocupação com a representatividade numérica, mas, sim, com o aprofundamento da compreensão de um grupo social ou de uma organização.

Os instrumentos de coleta de dados foram a pesquisa bibliográfica, análise documental da escola, e aplicação de entrevistas junto a gestora da escola e a professores(as) do $4^{\circ}$ ano do ensino fundamental. De acordo com Marconi e Lakatos (2003), a pesquisa bibliográfica objetiva aproximar o pesquisador de tudo o que já fora escrito sobre a temática abordada. Já a análise documental, recorre a diversas fontes, tais como: tabelas estatísticas, revistas, sites eletrônicos e documentos oficiais (FONSECA, 2002).

Nas entrevistas, o questionário foi divido entre questões referentes ao currículo escolar, à formação dos professores e práticas pedagógicas. Segundo Minayo (2010), as entrevistas proporcionam a valorização e compreensão das percepções, das opiniões e das interpretações dos indivíduos participantes, referentes a sua forma de pensar e se posicionar.

As informações obtidas foram tabuladas em planilhas, sistematizadas e os resultados são apresentados pelo método descritivo. Neste método, realiza-se o estudo, a análise, o registro e a interpretação dos fatos sem a interferência do pesquisador (BARROS; LEHFELD, 2007), sendo utilizados tabelas e gráficos para a discussão dos resultados, construídos a partir da estatística descritiva.

\section{Resultados e discussão}

\section{A realidade da formação do professor em escolas ribeirinhas}

A escola analisada possui centralidade na vida dos moradores das comunidades que atende. Nesse espaço, ocorrem as reuniões comunitárias referentes aos mais diversos temas, como organização das festas religiosas, campeonatos de futebol, cursos de capacitação para agricultura e reuniões da associação de produtores. É, portanto, um ambiente diferenciado das escolas urbanas, voltadas estritamente para a escolarização. 
Os professores da escola moram na comunidade e todos possuem curso superior, inclusive alguns têm até mais de uma graduação, realidade diferenciada de outras escolas rurais do Brasil, cuja maioria dos professores (91\%) não possui curso superior (BOF et al, 2006). Esse fato pode ser explicado pela proximidade da comunidade com a capital Manaus, sendo possível ida e volta à cidade no mesmo dia, o que possibilita aos professores a frequência em cursos presenciais.

Apesar da formação superior, a maioria dos professores da escola não possui uma formação específica em educação do campo. As ações governamentais voltadas à melhoria das condições de educação nas áreas rurais são orientadas pelas diretrizes da "Educação do e no campo", contrapondo-se ao modelo urbano e tecnocrata de educação, cuja principal preocupação é preparar os educandos para o mercado de trabalho. Na educação do campo é proposta a inclusão de orientações a respeito da cidadania, habitação, relações sociais, culturais e formação étnico-social (FERREIRA; BRANDÃO, 2011).

A Resolução No. 2, de 28 de abril de 2008, da Câmara de Educação Básica, do Conselho Nacional de Educação - Ministério da Educação, compreende educação do campo em seu artigo $1^{\circ}$ como:

- A Educação do Campo compreende a Educação Básica em suas etapas de Educação Infantil, Ensino Fundamental, Ensino Médio e Educação Profissional Técnica de nível médio integrada com o Ensino Médio e destina-se ao atendimento às populações rurais em suas mais variadas formas de produção da vida - agricultores familiares, extrativistas, pescadores artesanais, ribeirinhos, assentados e acampados da Reforma Agrária, quilombolas, caiçaras, indígenas e outros. (BRASIL, 2008, p. 1).

A educação do campo possui então um conceito diferenciado da educação urbana, tendo um significado que incorpora os espaços das florestas, da pecuária, das minas e da agricultura (BRASIL, 2012), necessitando, portanto, de uma formação específica. Mesmo não tendo essa formação pedagógica voltada para atuação no campo, os professores relataram não sentir necessidade dessa especialização para atuar na escola ribeirinha, visto que, segundo eles, aprenderam na experiência a adaptar-se pedagogicamente diante das dificuldades. Este fato remete a Silva (2012), quando afirma que a situação de desamparo vivida por muitos professores no Brasil, dada a precariedade estrutural de algumas escolas, desestimula o professor a continuar aprendendo e melhorando suas práticas. Ferreira (2003) alerta também que o estímulo à formação continuada vai além do oferecimento de cursos de capacitação, pois devem ser providenciados recursos materiais e financeiros para estimular o professor a uma contínua adaptação e atualização de suas práticas.

A falta de formação continuada reflete de maneira negativa na prática do professor, resultando no comodismo e na repetição de velhas práticas, em detrimento das realidades que estão constantemente em mudança. Essa acomodação pode ocorrer por inúmeros fatores, como baixo salário, precárias condições de trabalho e a própria falta de formação (FERREIRA, 2003).

0 comodismo afeta também de maneira negativa na aprendizagem do educando, pois o professor, nesses casos, não possui perspectiva de mudança e renovação de suas 
práticas educacionais. Assim, não proporciona metodologias novas e diferenciadas, e não busca a adaptação, tornando sua aula monótona e desgastante, consequentemente, incorrendo no desinteresse dos alunos.

São necessárias ações de estímulo aos professores para a busca de atualização e formação continuada. A formação possibilita a compreensão de novas propostas, práticas e caminhos que promovam o avanço educacional no que diz respeito ao processo de aprendizagem (CANEN; XAVIER, 2011). A formação continuada permite ainda que o professor reflita criticamente acerca de sua prática, possibilitando a evolução de sua ação docente (FREIRE, 1996).

0 processo de preparação do professor para atuar na realidade ribeirinha deve dotá-lo de mecanismos para a resiliência pedagógica, possibilitando a reflexão de suas dificuldades e fornecendo-lhes subsídios para novos métodos de ensino. Ao adquirir a capacidade de resiliência pedagógica, os professores estarão mais preparados para o atendimento das demandas escolares e sociais (MACHADO et al., 2015).

0 que se observa nas escolas ribeirinhas do Amazonas é o reflexo de cursos de graduação em pedagogia ainda distantes do preparo holístico e multidimensional do professor. Os professores são formados com limitadas habilidades para atuação em ambiente diferenciado da escola urbana, pois as teorias aprendidas na graduação muitas vezes não se adequam à realidade rural amazônica. As teorias do desenvolvimento cognitivo de Piaget e Wallon, por exemplo, dizem que o educador deve respeitar as fases de desenvolvimento cognitivo e motor das crianças, respeitando e preservando o ambiente no qual estão inseridas (MOREIRA, 1999). Entretanto, muitas vezes isso não se adequa à realidade das escolas ribeirinhas, pois o professor precisa dar conta de uma sala multiseriada, sem professor(a) auxiliar e sem materiais didáticos suficientes.

A maioria dos cursos de formação docente são voltados para os sistemas educacionais urbanos (VIGHI, 2013) e poucos investimentos públicos são observados para o preparo de docentes destinados à atuação no ambiente rural (ARROYO, 2007). É necessário investir nas escolas ribeirinhas do Amazonas os princípios da "educação DO campo" com processos construídos COM os sujeitos e não PARA os sujeitos, considerando suas especificidades e necessidades.

0 preconceito existente em torno da educação do campo é outro fator limitante para os avanços educacionais nessas áreas e os cursos de formação de professores necessitam contribuir para a quebra desse paradigma. Existe um imaginário coletivo de que a cidade é o espaço de sociabilidade primacial, trazendo uma noção de que as áreas rurais são atrasadas, e que "ser educado" é ser preparado para viver na cidade. 0 rural aparece apenas como o local da produção agropecuária, do atraso, da pobreza, da carência de serviços públicos, sendo visto como "sobra” dos munícipios (BOF et al., 2006).

É necessária a desconstrução dessa ideologia, estimulando-se a adoção de práticas de valorização e respeito ao ambiente rural no processo de escolarização das escolas rurais, observando-se como diferente, mas não inferior. É importante estimular os profissionais a problematizar as situações vivenciadas, viabilizando a construção de um conhecimento que vá além das paredes da escola (quando há paredes) e dos livros didáticos, procurando formas de garantir a aprendizagem atrelada às formas de organização social, às fontes de 
renda, às formas de produzir, aos tipos de alimentação e aos diversos aspectos vivenciados nessas áreas (BERNADI et al., 2014).

O Plano Nacional de Educação (PNE) aprovado pela Lei $\mathrm{N}^{\circ} 10.172$, de 9 de janeiro de 2001, tem como objetivo implementar até 2024, programas específicos para formação de profissionais da educação para as escolas do campo, de comunidades indígenas e quilombolas e para a educação especial (BRASIL, 2001). Alguns programas foram criados e supostamente estão sendo aplicados com objetivo de capacitar de maneira adequada os profissionais que atuam nessas escolas.

Entretanto, em 2016, o Instituto Nacional de Estudos e Pesquisas Educacionais Anísio Teixeira (INEP) divulgou um relatório de monitoramento das metas do PNE 2014 (BRASIL, 2016). Das 20 metas previstas, nenhuma havia sido cumprida integralmente após quase quinze anos de elaboração do plano. Observa-se, portanto, que apesar da existência de leis para garantia de uma educação qualificada e com equidade, estas não são postas em práticas, e tampouco são observadas atualmente ferramentas e instrumentos que vislumbrem alguma mudança nesse cenário.

A realidade observada na escola analisada nos permite inferir que as escolas ribeirinhas não estão apenas à margem dos rios, mas também à margem das políticas públicas. É preciso investir em programas de formação docente para esses ambientes, garantindo formações específicas que ajudem o professor em sua resiliência pedagógica, orientando-o a respeito das tecnologias disponíveis para realização de seu trabalho, de acordo com a realidade vivenciada.

\section{As adaptações curriculares na escola ribeirinha}

0 currículo educacional da escola analisada foi construído seguindo as orientações dos Parâmetros Curriculares Nacionais (PCN'S), elaborados em 1996 pela Lei de Diretrizes e Bases da Educação Nacional. Esses parâmetros têm como finalidade orientar o educador nos conteúdos que devem ser ensinados em cada modalidade de ensino, dando o suporte e norteamento necessários para a elaboração dos currículos escolares no Ensino Fundamental, adaptando-os às suas particularidades locais (BRASIL, 1996).

Assim como os PCN'S, as Diretrizes Curriculares Nacionais possuem origem na LDB, e foram elaboradas com a finalidade de orientar o planejamento do currículo escolar sobre cada modalidade de ensino e suas respectivas disciplinas, tanto para o ensino fundamental, quanto para o ensino médio. Esses documentos objetivam estabelecer a equidade da aprendizagem, assegurando que todos os estudantes tenham acesso aos conteúdos básicos de ensino, respeitando a sua realidade (BRASIL, 1996).

0 currículo é um importante auxílio para o processo de resiliência pedagógica do professor, visto que não aborda apenas as disciplinas, mas orienta também a aplicabilidade do conhecimento a ser adquirido pelo educando. Segundo Lopes e Macedo (2011, p. 54), o currículo pode ser compreendido como "uma ideia de organização, prévia ou não, de experiências/situações de aprendizagem realizada por docentes/redes de ensino, de forma a levar a cabo um processo educativo". 
No ambiente escolar, o currículo direciona e estrutura toda a prática educativa e, segundo Pereira (2012), é importante que a comunidade participe de sua construção, devendo ser elaborado não somente baseado nas leis educacionais e nas concepções do corpo docente, mas também envolvendo os anseios e necessidades da comunidade.

Os professores da escola relataram que as comunidades locais opinam durante as reuniões de pais e mestres quanto à organização das atividades elaboradas a partir do currículo. Para Tomazoni (2013) é importante que todos estejam envolvidos no processo de ensino e aprendizagem de uma escola, descentralizando as tomadas de decisões e possibilitando sua distribuição. A escola deve promover reuniões para participação efetiva dos pais nos debates escolares, contribuindo com suas opiniões acerca das ações educacionais que acreditam ser fundamental para a educação de seus filhos.

0 currículo educacional deve conciliar os conteúdos educacionais com a prática da cidadania, além do desenvolvimento das competências cognitivas e sociais (PADILHA et al., 2011). Porém, a educação para a cidadania é limitada sem uma formação especializada dos professores para atuação no ambiente ribeirinho, pois são necessárias habilidades específicas durante a construção do currículo, que possibilitem o aproveitamento do ambiente físico no qual a escola está inserida. Tescarolo (S/D) aponta que uma das dificuldades para construção de um currículo eficiente é que em muitas escolas o currículo produzido é uma verdadeira colcha de retalhos, com informações descontextualizadas e fragmentadas, embasadas por uma tradição pedagógica arcaica e insignificante e, portanto, sem produzir uma aprendizagem satisfatória e significativa para o desenvolvimento cognitivo dos discentes.

Para Saviani (2016), deve haver um currículo para cada região, um currículo para cada escola, quiçá, para cada classe, ou seja, o currículo deve respeitar e estar atento à realidade de sua escola. Deve-se também prever formas de flexibilização perante as adversidades que surgem ao longo do ano letivo, garantindo a resiliência pedagógica e facilitando a funcionalidade da prática educacional. Entretanto, as escolas rurais utilizam o mesmo currículo das escolas urbanas (PRAZERES; CARMO, 2011), descumprindo o que diz o Art. 28 da Lei de Diretrizes e Bases da Educação Nacional:

- Na oferta de educação básica para a população rural, os sistemas de ensino promoverão as adaptações necessárias à adequação das peculiaridades da vida rural e de cada região, especialmente: I - Conteúdos curriculares e metodologias apropriadas às reais necessidades e interesses dos alunos da zona rural. (BRASIL, 1996, p.10).

E como são tratadas como extensão do ensino urbano, as escolas rurais não recebem suporte adequado. A escola analisada nesse estudo não recebe suporte das secretarias de educação estadual e municipal. Conforme Art. 9 da Lei a Lei nº 9.394/96, o governo deve incumbir-se de:

- Prestar assistência técnica e financeira aos Estados, ao Distrito Federal e aos Municípios para o desenvolvimento de seus sistemas; de ensino e o atendimento prioritário à escolaridade obrigatória, exercendo sua função redistributiva e supletiva. (BRASIL, 1996, p. 12). 
Entretanto, os professores, juntamente com a gestora, reúnem-se para discutir as dificuldades da escola e elaboram vendas de alimentos, rifas e bingos para arrecadação de recurso financeiro para garantir a compra de materiais e até pagamentos de servidores. Silva (2012) diz que o governo, ao invés de assumir as responsabilidades sobre as escolas, acaba por algumas vezes criminalizando o profissional da educação pela falta de recursos e materiais, pois não repassando os recursos necessários para as atividades, os servidores são obrigados a agir por conta própria para suprir as deficiências.

Uma adaptação observada no currículo em relação aos períodos de seca e cheia é a flexibilidade do planejamento em relação aos conteúdos ministrados, principalmente durante a seca, que vai de junho a novembro na região. É nesse período que a escola enfrenta suas maiores dificuldades, pois conforme o rio seca e fica em baixo nível, os caminhos ficam mais longos, dificultando o acesso à escola.

Como a escola localiza-se distante do leito do rio, durante a seca as embarcações não conseguem se aproximar e as crianças e professores precisam caminhar até 50 minutos depois que deixam o barco para chegar à escola. Nesse período, são construídas pontes para facilitar a caminhada, pois o solo fica muito encharcado, correndo o risco de atolamento das pessoas no trajeto.

A gestora relatou que durante alguns anos a prefeitura envia ônibus para o transporte das crianças do barco até à escola. Todavia, na maioria do tempo os estudantes são transportados por um veículo chamado pela comunidade de "carrocinha" (figura 02), uma caminhonete com uma pequena carroça atracada que comporta cerca de 10 crianças, e por isso o motorista necessita fazer várias viagens para transportar todos os alunos. Ainda assim, a gestora afirmou que existem lugares em que a carrocinha não chega devido à falta de acesso por terra para que o veículo trafegue, resultando na falta dos estudantes à escola pela dificuldade de acessibilidade, além de ser um transporte perigoso, pois as crianças trafegam sentadas no chão, sem cobertura e nenhuma segurança.

Figura 02- Transporte escolar denominado "carrocinha"

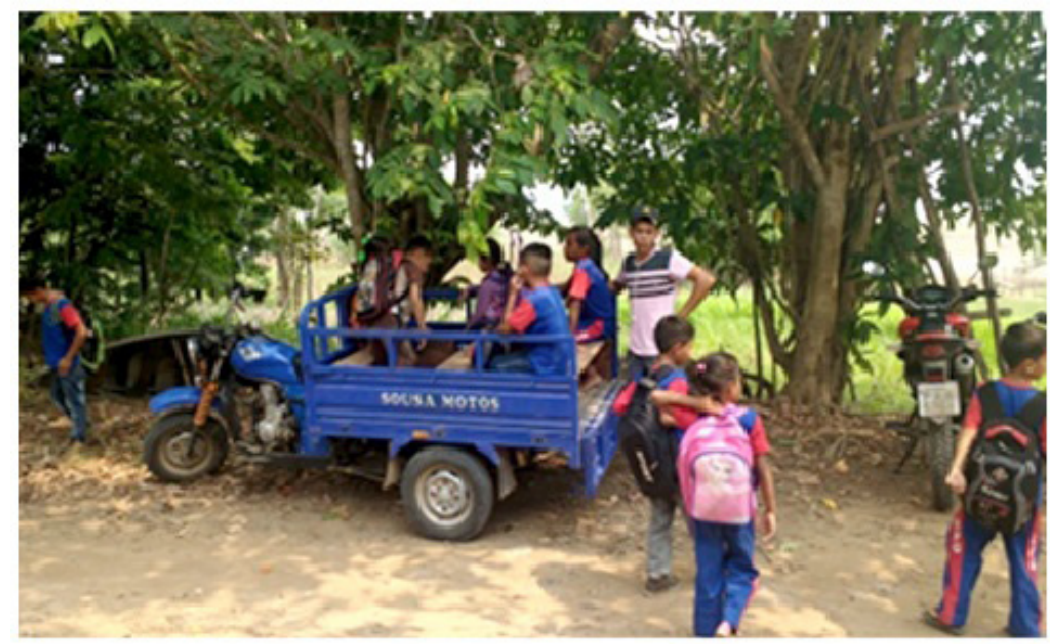

Fonte: Dados da pesquisa. 
Durante a cheia, as dificuldades também existem para os ribeirinhos e, consequentemente, para as escolas de várzea. Nesse período que vai de dezembro a maio na região, os rios aumentam seus níveis, impossibilitando os cultivos agrícolas, além de algumas vezes inundar as residências e a escola. As crianças conseguem chegar de barco à escola com maior facilidade, porém, há os riscos de afogamentos e acidentes com cobras e jacarés (bastante frequentes no local), e como algumas famílias não possuem canoa (pequena embarcação), dependem dos vizinhos para o transporte até à escola.

Entretanto, é no período de seca que ocorre uma considerável evasão escolar. Para minimizar esse problema, os professores reduzem os conteúdos curriculares, selecionando aqueles que são pré-requisitos para a série seguinte, na tentativa de minimizar os prejuízos aos estudantes que não conseguem chegar à escola durante a seca.

A evasão escolar deve gerar reflexão na escola e devem ser verificadas estratégias para evitá-la. Pode ocorrer por inúmeros motivos, ligados aos mais diversos contextos, gerando variados prejuízos sociais, principalmente ao estudante, que tem sua aprendizagem prejudicada pela falta de acompanhamento e continuidade dos estudos. Dentre as principais consequências, tem-se a permanência da desigualdade social, pois a baixa escolaridade dificulta o acesso ao mercado de trabalho e outras estratégias de obtenção de renda na fase adulta (SANTANA et al., 2015).

Os professores informaram que não adotam nenhuma metodologia específica na redução dos conteúdos. Larchert (2010) diz que o professor pode selecionar os conteúdos curriculares a partir de uma decisão de intencionalidades, sendo de sua responsabilidade escolher os conteúdos que desenvolverão aprendizagens nos alunos. Entretanto, essa seleção e organização não é uma simples listagem, o educador deve planejar a seleção de acordo com as necessidades futuras dos alunos.

A adaptação dos conteúdos curriculares de acordo com as necessidades dos educandos é um bom mecanismo para o processo de resiliência pedagógica, entretanto, é necessária a adoção e sistematização de uma metodologia baseada em princípios científicos para garantir uma aprendizagem satisfatória do currículo básico, oportunizando aos estudantes das áreas rurais o acesso universal ao conhecimento e a igualdade de oportunidades, evitando a seleção dos conteúdos a partir de "achismos".

\section{Práticas no processo de resiliência pedagógica em escolas ribeirinhas}

A capacidade de resiliência é necessária em diversos âmbitos, principalmente no ambiente educacional, considerando a flexibilidade e equilíbrio necessários perante os constantes desafios. Conforme Samaniego e Boufler (2017), os professores parecem cada vez mais desanimados com a sua realidade, devido a inúmeros fatores, mas principalmente pelas complexidades que variam entre má remuneração, falta de material pedagógico, dificuldades de aprendizagem e ausência de auxílio. Essa situação tem incentivado os estudos sobre resiliência no campo educacional, porém, ainda incipientes.

A resiliência pedagógica pode ser conceituada como a capacidade de adaptação do professor perante os desafios existentes no seu cotidiano, utilizando suas habilidades 
pessoais e comportamentais (criatividade, autonomia, paciência, dentre outros), juntamente com instrumentos pedagógicos (currículo, livros, atividades, projetos, entre outros) para solucionar ou minimizar os problemas da escola. A partir desses fatores, a resiliência pedagógica pode ser definida nas etapas identificadas na figura 03.

Figura 03 - Etapas da resiliência pedagógica

\section{Resiliência Pedagógica}

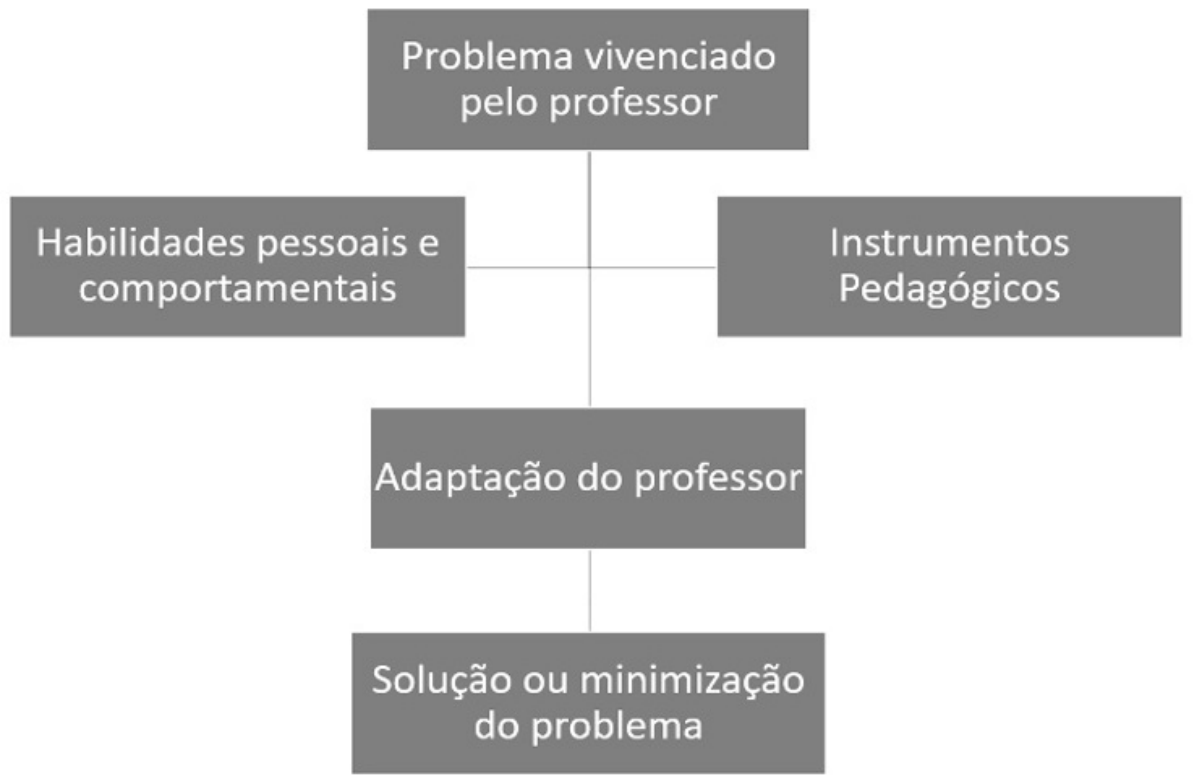

Fonte: Elaboração própria.

A aquisição da capacidade de resiliência pedagógica auxilia na prática de uma construção mútua do conhecimento entre estudante e professor. Aprendendo com o outro na adaptação de suas realidades e identidades, compartilham não apenas a aprendizagem de conteúdos curriculares, mas experiências de vida, tornando a aprendizagem menos fragmentada, considerando os diferentes ambientes em que ela se dá (VERDUM, 2011).

No caso das escolas ribeirinhas, a resiliência pedagógica permeia uma realidade atrelada a imprevistos ambientais que dificultam a chegada dos estudantes e professores à escola, além de estruturas físicas e pedagógicas precárias (MENDES et al., 2008). Esses fatores precisam ser considerados no processo de formação pedagógica, preparando o professor para as adversidades que encontrará em sua atuação profissional.

Portanto, os mecanismos necessários à aquisição da capacidade de resiliência pedagógica devem ser oportunizados durante a formação do professor, viabilizando o contato dos professores com cenários educacionais diferenciados, como as escolas rurais ribeirinhas, dando-lhes caminhos para se adequar às inúmeras situações inesperadas 
existentes nesse ambiente. Os principais valores necessários à resiliência pedagógica são: autonomia, eficácia, habilidade de reconhecimento, tolerância, paciência e mediação de problemas (ANGST, 2009).

Como os recursos externos são escassos, os professores da escola analisada elaboram seus próprios materiais didáticos, o que pode ser observado na fala de uma professora: "Nós já sabemos que temos que ter o Plano A e o Plano B, se não, as nossas aulas não saem”. Os professores afirmaram que para superar as limitações da infraestrutura, procuram adotar uma metodologia diversificada, como trabalho em grupo, seminários, aulas expositivas, aulas dialogadas e aulas práticas.

As adaptações estruturais e curriculares necessárias para superar os desafios de uma escola em ambiente de várzea são realizadas de maneira coletiva na escola analisada: "Trabalhamos em coletividade ouvindo a ideia de cada um" (fala de professora). Os educadores procuram inserir em suas aulas o ambiente geográfico, o modo de vida, a cultura e os costumes pertinentes à comunidade.

Os professores procuram minimizar a redução do tempo e dos conteúdos durante o período de seca por meio de aulas expositivas diferenciadas e atividades diversificadas. Observa-se que apesar das limitações enfrentadas na escola analisada, como falta de uma formação específica e continuada, evasão escolar, dificuldade de transporte para alunos e professores, dificuldade de acesso à escola, periculosidade do transporte e falta de recursos físicos e financeiros, os professores demonstram boa capacidade de resiliência, adaptando-se de forma satisfatória às adversidades da escola.

Paulo Freire afirma que a educação está intrinsecamente relacionada com a resiliência (FREIRE, 1992). Para o autor, a educação não deve tratar apenas dos conteúdos curriculares, mas deve abordar todo o contexto social do educando. 0 professor deve estar preparado e preparar os estudantes para o enfrentamento das diferentes realidades que os cercam (RAYMUND0; LEÃO, 2013).

Ao ser resiliente, o professor possibilita a construção de uma aprendizagem significativa e de qualidade, proporcionando ferramentas para a superação de situações problemas no âmbito escolar, em detrimento à mera repetição dos modelos prontos repassados pelas secretarias de educação (ARROYO, 2007).

Há necessidade da elaboração de políticas públicas que promovam uma formação voltada para todas as realidades educacionais. 0 professor necessita da aquisição de habilidades e valores para construção de sua capacidade de resiliência pedagógica, levando em consideração sua identidade social e as adversidades presentes em seu ambiente de ensino, considerando as inúmeras dificuldades presentes nas escolas, que vão desde a falta de infraestrutura até as práticas educativas inadequadas.

\section{Considerações finais}

Durante a realização desse estudo pôde-se perceber as variações existentes no ambiente escolar da área, não somente naturais, mas também sociais, econômicas e educacionais. Esse cenário apresenta a relevância da realização de pesquisas sobre resiliência pedagógica na educação do campo, e especificamente da educação ribeirinha, visto que ambas possuem relação intrínseca com o ambiente que as permeiam, dado 
que suas realidades sociais influenciam direta e indiretamente de maneira expressiva na educação de suas populações.

A maioria dos estudos referentes à educação ribeirinha elenca sempre questões referentes à falta de estruturas, tanto físicas quanto pedagógicas em grande parte dessas escolas. Entretanto, nesse estudo pôde-se verificar outras dificuldades, como os fatores que limitam a adaptação pedagógica do professor nestes ambientes.

Ao observar a realidade estudada, pôde-se perceber que o currículo construído pelo corpo docente possui uma estrutura semelhante ao currículo urbano. Ainda assim, os professores constroem o seu planejamento considerando a sua realidade, tentando se adaptar, ainda que de maneira parcial, às situações que surgem anualmente.

Destaca-se nesse sentido a importância de um currículo construído a partir dos ideais e perspectivas de cada escola e que atenda suas necessidades. Faz-se necessário pensar e colocar em prática uma educação específica para esses ambientes, considerando seus variados contextos.

0 estudo apontou também a ausência de uma formação específica aos professores para atuarem na realidade ribeirinha, além de raramente receberem formação continuada para atualização de suas práticas. A falta dessa formação limita a utilização de todo potencial do ambiente ribeirinho para a construção de metodologias educacionais específıcas.

0 professor sente-se desmotivado para a busca de especialização e formação continuada devido a inúmeros fatores que vão desde o financeiro até o pedagógico. Dessa forma, alguns educadores não utilizam a pesquisa para construção de práticas pedagógicas diferenciadas, que poderiam propiciar uma aprendizagem mais significativa e que respondessem aos problemas enfrentados nestes locais.

0 professor ribeirinho é obrigado a se adaptar anualmente para ministrar suas aulas em diferentes períodos sazonais (seca e cheia do rio). São reelaborações curriculares, planejamentos, mudanças de aulas e criação de práticas. Mas não apenas isso. Os professores e gestores também necessitam se adaptar à falta de material e infraestrutura, promovendo iniciativas próprias para a arrecadação de recursos.

Outro ponto que pode ser destacado, é a necessidade de uma maior atenção por parte das Secretárias de Educação e órgãos relacionados às escolas presentes nas comunidades ribeirinhas. Algumas escolas vivem em situação de abandono, o que afeta não somente a aprendizagem dos estudantes, mas também o processo de resiliência pedagógica do professor.

Portanto, é importante incentivar a elaboração de políticas que promovam a preparação física, psicológica e pedagógica para que o professor alcance a capacidade de se adaptar. Com essa resiliência, o professor conseguirá não apenas repassar os conteúdos curriculares exigidos, mas também proporcionar a prática da reflexão e criticidades, desenvolvendo e construindo um conhecimento que permitirá que o sujeito possa agir de maneira efetiva e significativa para mudança do seu meio social.

\section{Referências}

ANGST, Rosana. Psicologia e resiliência: uma revisão de literatura. Revista Psicologia Argumento, Curitiba, v. 27, n. 58, p. 253-260, 2009. 
ARROYO, Miguel Gonzáles. Indagações sobre currículo: educandos e educadores - seus direitos e 0 currículo. In: BRASIL. Ministério da Educação. Indagações sobre o currículo do ensino fundamental. Brasília, DF: MEC, 2007. p. 1-52.

BARROS, Aidil Jesus da Silveira; LEHFELD, Neide Aparecida Souza. Fundamentos de metodologia científica. São Paulo: Prentice-Hall, 2007.

BERNADI, Luci dos Santos; PELINSON, Nadia Cristina Picinini; SANTIN, Rosemeri. 0 desafio de ser professor na escola do campo: o contexto da casa familiar rural Santo Agostinho. Revista Reflexão e Ação, Santa Cruz do Sul, v. 22, n. 2, p.120-142, jul./dez. 2014.

BOF, Alvana Maria et al. A educação no Brasil rural. Brasília, DF: Inep, 2006.

BRASIL. Resolução No. 2 de 28 de abril de 2008. Brasília, DF: MEC, 2008. Disponível em: http://portal. mec.gov.br/arquivos/pdf/resolucao_2.pdf. Acesso em: 12 jun. 2019.

BRASIL. Instituto Nacional de Estudos e Pesquisas Educacionais Anísio Teixeira. Relatório do $1^{\circ}$ ciclo de monitoramento das metas do PNE: biênio 2014-2016. Brasília, DF: Inep, 2016.

BRASIL. Ministério da Educação. Lei nº 9.394 de 20 de dezembro de 1996: Diretrizes e Bases da Educação. Brasília, DF: MEC, 1996.

BRASIL. Ministério da Educação. Lei № 10.172, de 9 de janeiro de 2001: Plano Nacional de Educação. Brasília, DF: Inep, 2001.

BRASIL. Ministério da Educação. Secretaria de Educação Continuada, Alfabetização, Diversidade e Inclusão. Educação do campo: marcos normativos / Secretaria de Educação Continuada, Alfabetização, Diversidade e Inclusão. Brasília, DF: Secadi, 2012.

BRITO, Daniel Bezerra de. Histórias de vida e saberes docentes das educadoras da zona urbana e rural. Educação \& Realidade, Porto Alegre, v. 40, n. 3, p. 923-945, jul./set. 2015.

CANEN, Ana; XAVIER, Giseli Pireli de Moura. Formação continuada de professores para a diversidade cultural: ênfases, silêncios e perspectivas. Revista Brasileira de Educação, Belo Horizonte, v. 16, n. 48, p. 641-813, 2011.

CASTRO, Maria Aparecida Campos Diniz de. Revelando o sentido e o significado da resiliência na preparação de professores para atuar e conviver num mundo em transformação. In: TAVARES, José (org.). Resiliência e educação. São Paulo: Cortez, 2001. p. 115-126.

FERREIRA, Fabiano de Jesus; BRANDÃO, Elias Canuto. Educação do campo: um olhar histórico, uma realidade concreta. Revista Eletrônica de Educação, São Carlos, n. 9, p. 58-71, jul./dez. 2011.

FERREIRA, Jorge Carlos Felz. Reflexões sobre o ser professor: a construção de um professor intelectual. Biblioteca Online de Ciências da Comunicação, São Paulo, 2003. Disponível em: http://www.bocc.ubi. pt/pag/felz-jorge-reflexoes-sobre-ser-professor.pdf. Acesso em 05 jan. 2019. 
FONSECA, João José Saraiva. Metodologia da pesquisa científica. Fortaleza: UEC, 2002.

FREIRE, Paulo. Pedagogia da autonomia: saberes necessários à pratica educativa. Rio de Janeiro: Paz e Terra, 1996.

FREIRE, Paulo. Pedagogia da esperança, um reencontro com a pedagogia do oprimido. Rio de Janeiro: Paz e Terra, 1992.

GERHARDT, Tatiana Engel; SILVEIRA, Denise Tolfo. Métodos de pesquisa. Porto Alegre: UFRGS, 2009.

GROTBERG, Edith Henderson. Introdução: Novas tendências em resiliência. In: MELILLO, Aldo et al. (org.). Resiliência: descobrindo as próprias fortalezas. Porto Alegre: Artmed, 2005. p. 15-22.

LARCHERT, Jeanes Martins. 0 planejamento pedagógico e a organização do trabalho docente. Ilhéus: UESC, 2010. Disponível em: http://educamoc.com.br/ckfinder/files/didatica.pdf. Acesso em: 01 jun. 2019.

LOPES, Alice Casimiro; MACEDO, Elizabeth. Teorias de currículo. São Paulo: Cortez, 2011.

MACHADO, Ana Carolina et al. Estar resiliente: uma estratégia pedagógica para professores da escola pública. 2015. 51 f. Trabalho de Conclusão de Curso (Graduação em Psicologia) - Centro Universitário Anhanguera de Santo André, Santo André, 2015.

MARCONI, Maria de Andrade; LAKATOS, Eva Maria. Metodologia do trabalho científico. São Paulo: Atlas, 2003.

MENDES, Leila Said Assef Mendes et al. A prática docente em uma escola ribeirinha na ilha do Marajó: um estudo preliminar em contexto naturalístico. Revista Educação, Porto Alegre, v. 31, n. 1, p. 80-87, 2008.

MINAYO, Maria Cecília de Souza. 0 desafio do conhecimento: pesquisa qualitativa em saúde. São Paulo: Hucitec, 2010.

MOREIRA, Marco Antônio. Teorias de aprendizagem. São Paulo: Pedagógica e Universitária, 1999.

NASCIMENTO, Ana Cristina Lima do. Resiliência e adaptabilidade dos sistemas socioecológicos ribeirinhos frente a eventos climáticos extremos na Amazônia Central. 2017. 134 f. Dissertação (Mestrado em Ciências do Ambiente e Sustentabilidade na Amazônia) - Universidade Federal do Amazonas, Manaus, 2017.

PADILHA, Paulo Roberto et al. Educação para a cidadania planetária: currículo intertransdisciplinar em Osasco São Paulo: Instituto Paulo Freire, 2011.

PEREIRA, Charlene Alana Altieri. A construção do currículo na gestão democrática. Revista Paulista de Educação, São Paulo, v. 1, n. 1, p. 56-70, 2012.

PRAZERES, Maria Sueli Corrêa dos; CARMO, Eraldo Souza do. Educação do campo e políticas públicas na Amazônia: desafios e possibilidades. In: SIMPÓSIO BRASILEIRO DE POLÍTICA E ADMINISTRAÇÃO DA EDUCAÇÃO, 25. [e] CONGRESSO IBERO-AMERICANO DE POLÍTICA E ADMINISTRAÇÃO DA EDUCAÇÃO, 2. 2011, São Paulo. Anais eletrônicos... São Paulo: ANPAE, 2011. p. 1-13. Disponível em:http://www.anpae. org.br/simposio2011/cdrom2011/PDFs/trabalhosCompletos/posters/0104.pdf. Acesso em: 08 abr. 2019. 
RAYMUND0, Rosana Salles; LEÃ0, Marluce Auxiliadora Borges Glaus. A resiliência como fator de desenvolvimento da prática pedagógica: pensando a formação docente e sua relação com a comunidade. Revista de Ciências da Educação, São Paulo, v. 02, n. 29, p. 55-66, 2013.

RODRIGUES, Ernaldina Souza Silva. A organização do tempo pedagógico no trabalho docente: relações entre o prescrito e o realizado. 2009. 116 f. Dissertação (Mestrado em educação) - Universidade Metodista de Piracicaba, São Paulo, 2009.

SAMANIEGO, Jonatan Guilherme Silva; BOUFLEUR, Emne Mourad. Resiliência e educação: como o professor e sua metodologia podem desenvolver habilidades de enfrentamento às adversidades. Revista Magsul de Educação da Fronteira, Ponta Porã, v. 2, n. 1, p. 221-250, 2017.

SANTANA, Maria Rosangela; SILVA, Braz Ribeiro; GUIMARÃES, Marialvone Pereira.As causas e consequências da evasão escolar na educação de jovens e adultos. Revista Científica Semana Acadêmica, Fortaleza, n. 74, p. 1-13, 2015. Disponível em: https://semanaacademica.org.br/artigo/causas-e-consequencias-daevasao-escolar-na-educacao-de-jovens-e-adultos. Acesso em: 15 maio 2019.

SAVIANI, Dermeval. Educação escolar, currículo e sociedade: o problema da base nacional comum curricular. Movimento Revista de Educação, Niterói, v. 3, n. 4, p. 54-84, 2016.

SILVA, Daniella Neves da. A desmotivação do professor em sala de aula nas escolas públicas do município de São José dos Campos-SP. 2012. 51 f. Monografia (Especialização em Gestão Pública) Universidade Tecnológica Federal do Paraná, Curitiba, 2012.

TAVARES, José. Resiliência e equilíbrio emocional na escola. Revista Conhecimento \& Diversidade, Niterói, n. 11, p. 65-78, jan./jun. 2014.

TESCAROLO, Ricardo. Currículo escolar: limites e possibilidades. [S. I.: s. n.: s. d.]. Disponível em: http:// www.colegiosantanna.com.br/formacao/downloads/texto2.pdf. Acesso em: 05 maio 2019.

TOMAZONI, Jucemara Luciana Gandini. A importância da participação da comunidade na elaboração do projeto político pedagógico para um ensino de qualidade. 2013. 43 f. Monografia de especialização (Especialização em Gestão Educacional) - Universidade Federal de Santa Maria, Santa Maria, 2013.

VERDUM, Priscila de Lima. Prática pedagógica: 0 que é? 0 que envolve? Revista Educação por Escrito, Porto Alegre, v.4, n. 1, p. 91-105, 2011.

VIGHI, Cátia Simone Becker. Da escola na zona urbana para a escola do/no campo: os professores em foco. 2013. 128 f. Tese (Doutorado em Ciências da Educação) - Faculdade de Educação da Universidade Federal de Pelotas, Pelotas, 2013. 
Danielle Golvim da Silva Alencar é mestranda em educação pelo Instituto Federal do Amazonas (IFAM). Fez graduação em pedagogia na Universidade Federal do Amazonas (UFAM). É especialista em investigações educacionais pelo Instituto Federal do Amazonas (IFAM).

Francimara Souza da Costa é professora adjunta na Faculdade de Ciências Agrárias (FCA) da Universidade Federal do Amazonas (UFAM). Doutora em ciências socioambientais pelo Núcleo de Altos Estudos Amazônicos (NAEA) da Universidade Federal do Pará (UFPA). Desenvolve pesquisa e extensão em agroecologia, desenvolvimento rural e sustentabilidade socioambiental. 